Gut, 1975, 16, 209-213

\title{
The effect of wheat bran on intestinal transit
}

\author{
D. K. PAYLER, E. W. POMARE, K. W. HEATON ${ }^{1}$, AND R. F. HARVEY \\ From Malvern College, Worcs, and the University Department of Medicine, Royal Infirmary, Bristol
}

SUMMARY In 18 students and two members of staff at a boys' boarding school, the time taken to pass 20 out of 25 radiopaque pellets varied from one to seven days while the subjects were eating a normal English diet. After the addition of bran, about $20 \mathrm{~g}$ daily, to this diet transit time fell from $2.75 \pm 1.6$ to $2.0 \pm 0.9$ days $(P<0.025)$. Transit became faster in all nine subjects who had an initial time of three days or more, and in three of seven with an initial time of two days, but became slower in all four boys with an initial one-day transit. Frequency of defaecation correlated poorly with transit time (a once daily bowel action being found with transit times ranging from one to four days), and did not increase significantly with bran.

In 10 additional adults with slow initial transit (three or four days) the effect of bran was compared with that of an equal volume of ground oatflakes in a double-blind crossover trial. Bran caused a significant acceleration of transit, whereas oatmeal had no effect.

These studies confirm that bran accelerates slow intestinal transit and show that this is not simply a psychological effect. Bran may also slow down fast transit.

Disorders of the large bowel such as colon spasm, appendicitis, diverticular disease, and carcinoma, which are very common in civilized societies, are apparently uncommon in primitive communities. This difference in disease patterns has been linked with a difference in intestinal transit times, the suggestion being that the 'normal' intestinal transit of civilization is in fact pathologically slow, due to consumption of fibre-depleted foods (Burkitt, Painter, and Walker, 1972). This concept, which has long been put forward by Walker (1947 and 1974), assumes that dietary fibre accelerates colonic transit, presumably by increasing stool bulk. However, actual data on how fibre affects transit are scant and conflicting. In 1973 Harvey, Pomare, and Heaton, studying 20 normal subjects and patients with the irritable bowel syndrome, and using a radiopaque pellet technique, reported that wheat bran (about $\mathbf{3 0} \mathrm{g}$ per day) accelerated intestinal transit when it was initially slower than average but slowed it when it was initially faster. Eastwood, Kirkpatrick, Mitchell, Bone, and Hamilton (1973) used the same technique in eight normal subjects, and stated that bran had no significant effect on intestinal transit. Kirwan, Smith, McConnell, Mitchell, and Eastwood (1974) reported that $20 \mathrm{~g}$ daily of a coarse bran accelerated slow transit, Received for publication 7 January 1975.

${ }^{1}$ Requests for reprints to $\mathrm{K}$. W. $\mathrm{H}$. whereas the same amount of fine bran had no effect. In view of these discrepancies, it seemed desirable to investigate this matter further and in particular to carry out a controlled study to exclude possible pyschological effects of feeding bran upon intestinal function.

This paper reports two separate studies on the effect of bran upon intestinal transit, one of which was carried out as a double-blind controlled trial.

\section{Subjects and Methods}

\section{FIRST STUDY}

This was carried out in a boys' boarding school on 20 healthy Caucasian volunteers. These consisted of 18 boys aged 16-18, one male staff member aged 48 , and one female staff member aged 60 . The latter regarded herself as constipated but all the others considered that they had normal bowel habits. The usual school diet was eaten by all subjects during the first set of measurements. Actual food intakes were not recorded, but every person's diet included ordinary amounts of white flour and refined sugar. Normal activities continued throughout the whole study.

Transit time of food residues from mouth to anus was measured by the technique of Hinton, LennardJones, and Young (1969), with minor modifications. Twenty-five barium-impregnated pellets (Portex 
Ltd, Hythe, Kent) were taken by mouth immediately after defaecation. The dates and times of defaecation were noted then and for the next five stools. These stools were collected and radiographed to determine their content of pellets. From these data were calculated the mean frequency of defaecation in stools per week and the time required to pass $80 \%$ of the pellets. This time was taken as the 'transit time', as recommended by Hinton et al (1969). After completing these baseline collections, each subject was asked to add to his diet each day two heaped dessertspoonfuls (approximately $10 \mathrm{~g}$ ) of unprocessed millers' wheat bran. This bran was of a coarse or flaky variety, which is known to contain about $33 \%$ of fibre, in the form of cellulose $6 \%$, hemicellulose $23 \%$, and lignin $4 \%$ (DAT Southgate, personal communication). Each subject also replaced white bread in his diet with a specially prepared wholemeal bread, which on average added a further $10 \mathrm{~g}$ of bran to the diet, giving a total daily intake of approximately $20 \mathrm{~g}$ bran. After three to six weeks, the above measurements were repeated while the subjects continued taking bran.

SECOND STUDY

This was a double-blind, crossover comparison of bran with a relatively low-fibre material, oatmeal. It was carried out in 10 Caucasian adults (two males, aged 36 and 53, and eight females, aged 31 to 64 ) who, in the course of clinical investigations, were found to have slow intestinal transit. Three were patients with the spastic colon syndrome, four had mild proctitis or procto-sigmoiditis, and one each had simple constipation, non-ulcer dyspepsia, and diverticular disease of the colon. The bran used was more powdery than in the first study (Bran-Plus, Allinson's Ltd). It was selected as being easier to match with a low-fibre contrast material. The latter consisted of Quaker breakfast oatflakes which had been machine ground to a particle size similar to that of the bran. The resulting material was similar in appearance and 'feel' to bran, but required less chewing due to its lower fibre content. Oatflakes have a 'crude-fibre' content of about $1.5 \%$ compared with $7.3 \%$ for the bran used here.

The design of the study was as follows: a baseline measurement of transit was obtained while the normal diet was eaten; the subject was then supplied with bran or ground oatflakes in a packet labelled only ' $A$ ', and asked to take one standard scoopful three times a day with meals but otherwise to

\begin{tabular}{|c|c|c|c|c|}
\hline \multirow[b]{2}{*}{ Subjects } & \multicolumn{2}{|l|}{ Before Bran } & \multicolumn{2}{|l|}{ With Bran } \\
\hline & $\begin{array}{l}\text { Transit Time } \\
\text { (days) }\end{array}$ & $\begin{array}{l}\text { Defaecations } \\
\text { per Week }\end{array}$ & $\begin{array}{l}\text { Transit Time } \\
\text { (days) }\end{array}$ & $\begin{array}{l}\text { Defaecations } \\
\text { per Week }\end{array}$ \\
\hline \multicolumn{5}{|l|}{ Boys } \\
\hline 1 & 3 & $7 \cdot 1$ & 1 & 8.0 \\
\hline 2 & 4 & 6.5 & 2 & $6 \cdot 0$ \\
\hline 3 & 4 & -2 & 3 & -2 \\
\hline 4 & 6 & -2 & 1 & -2 \\
\hline 5 & 2 & 7.8 & 2 & $7 \cdot 1$ \\
\hline 6 & 2 & 6.9 & 2 & 5.9 \\
\hline 7 & 2 & 7.9 & 2 & 9.0 \\
\hline 8 & 1 & 10.5 & 2 & 8.8 \\
\hline 9 & 2 & 8.8 & 2 & 10.5 \\
\hline 10 & 2 & 4.8 & 1 & 7.2 \\
\hline 11 & 2 & $7 \cdot 1$ & 1 & $7 \cdot 1$ \\
\hline 12 & 2 & 6.5 & 1 & $8 \cdot 7$ \\
\hline 13 & 4 & 6.8 & 3 & $6 \cdot 6$ \\
\hline 14 & i & $10 \cdot 4$ & 2 & $8 \cdot 8$ \\
\hline 15 & 1 & 6.7 & 2 & $7 \cdot 4$ \\
\hline 16 & $i$ & 6.5 & 2 & 6.0 \\
\hline 17 & 3 & 6.8 & 2 & $7 \cdot 2$ \\
\hline 18 & 3 & 6.9 & 2 & $7 \cdot 4$ \\
\hline \multicolumn{5}{|l|}{ Female } \\
\hline $60 y$ & 7 & $5 \cdot 6$ & 5 & $8 \cdot 4$ \\
\hline \multicolumn{5}{|l|}{ Male } \\
\hline $48 y$ & 3 & $7 \cdot 1$ & 2 & $7 \cdot 1$ \\
\hline $\begin{array}{l}\text { Mean } \\
\text { SD }\end{array}$ & $\begin{aligned} & 2 \cdot 75 \\
\pm & 1 \cdot 6\end{aligned}$ & $\begin{array}{r}7 \cdot 3 \\
\pm 1 \cdot 4\end{array}$ & $\begin{array}{r}2.0 \\
\pm 0.9\end{array}$ & $\begin{array}{r}7.6 \\
\pm 1.2\end{array}$ \\
\hline $\begin{array}{l}\text { Significance } \\
\text { of difference }\end{array}$ & & & $\begin{array}{c}t=-2.3795 \\
P<0.025\end{array}$ & $\begin{array}{l}t=1.1653 \\
P>0.10\end{array}$ \\
\hline
\end{tabular}

Table I Time taken to pass $80 \%$ of ingested radiopaque pellets and the frequency of defaecation in 18 sixth form boys and two staff members at a boys' boarding school ${ }^{1}$

${ }^{1}$ Data before and after adding to the diet about $20 \mathrm{~g}$ of bran daily.
${ }^{2}$ Less than five stools collected, so calculation not valid. 
continue his normal diet. After one week, the subject was asked to increase the 'dose' of $A$ to two scoopfuls three times daily. After a further two weeks, transit time was measured a second time. The subject was then given packet $\mathbf{B}$ containing the other material under study, and asked to take it in exactly the same way. Three weeks later, transit time was measured for the third and last time. Six scoopfuls of this bran weigh $\mathbf{4 0}$ grams. Five subjects had bran in packet $A$ and five in packet $B$, the order being randomly allocated among the 10 subjects. The contents of the packets were not known to the investigators until the end of the study. The significance of the results was assessed by Student's paired $t$ test using Bessel's correction.

Transit time was again taken as the time taken to pass 20 out of 25 radiopaque pellets but the data were obtained in a different way. The pellets were swallowed on retiring to bed, and radiographs of the abdomen were taken at 9-10 o'clock each morning until five or fewer pellets remained. Records of defaecation were too brief to permit accurate calculations of bowel frequency in this group.

\section{Results}

\section{FIRST STUDY}

While the normal school diet was being eaten, the time taken by the 20 subjects to pass 20 pellets varied between 23 and 157 hours. The frequency of defaecation was approximately once daily in all subjects (mean $7.3 \pm 1.4$ stools per week), so it seemed more appropriate to express transit time in days rather than hours (table I). There was little correlation between bowel frequency and transit time. Before bran the correlation was just significant $(r=-0.474, P<0.05)$, but with bran it was not significant $(r=-0.042)$. Subjects with a bowel frequency of six or seven stools per week had transit times which ranged from one to four days.

The effect of bran on transit time is detailed in table I and shown graphically in the figure. Overall, transit time was significantly reduced, from $2 \cdot 75 \pm$ 1.6 days to $2.0 \pm 0.9$ days $(\mathrm{t}=-2.380, \mathrm{P}<0.025)$. Acceleration of transit occurred in all nine subjects starting with a transit time of three days or longer, and in three out of seven subjects starting at two days. However, in each of the four subjects with an initial transit time of one day, the addition of bran slowed down the transit time to two days. If, because of this different response to bran, these four subjects are treated as a separate group, then the accelerating effect of bran on the main group of 16 becomes more significant. Thus, in the 16 subjects whose transit time was initially two days or

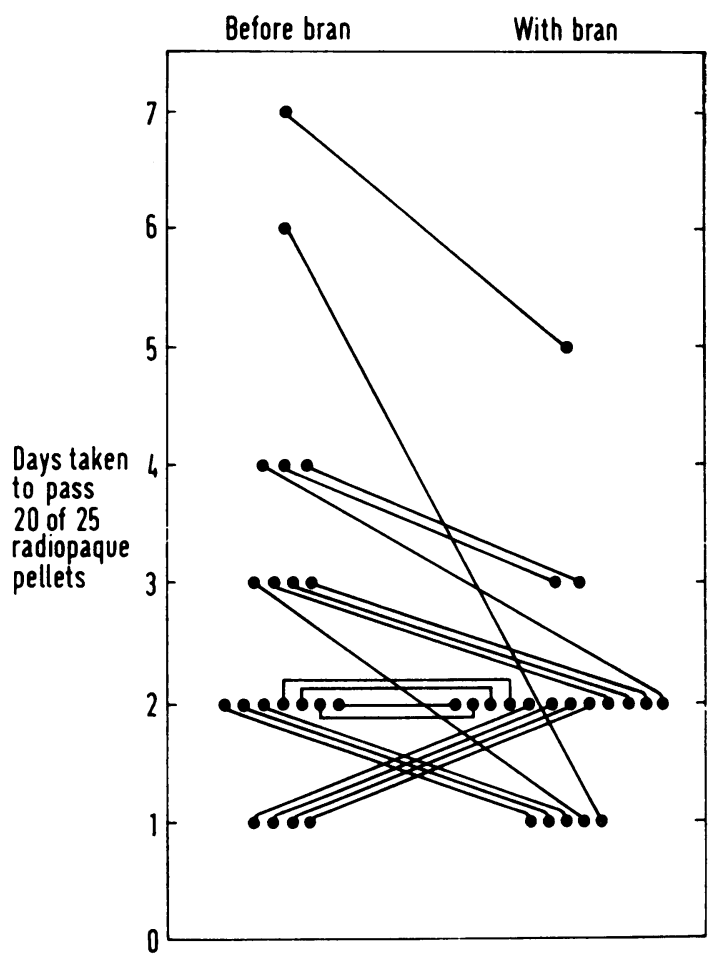

Fig Intestinal transit time in 20 subjects before and during the addition to the diet of bran, about $20 \mathrm{~g}$ daily.

more, transit time fell from $3 \cdot 2 \pm 1 \cdot 5$ to $2 \cdot 0 \pm 1 \cdot 0$ days $(t=-3.884, \mathrm{P}<0.0025)$.

The effect of bran on the frequency of defaecation was much less consistent than its effect on transit time. The overall change, from $7 \cdot 3 \pm 1.4$ to $7.6 \pm$ $1 \cdot 2$ stools per week was not significant $(t=1 \cdot 16 \overline{5}$, $P>0 \cdot 10)$.

\section{SECOND STUDY}

The mean transit time during the control period was

\begin{tabular}{|c|c|c|c|c|}
\hline Subject & Baseline & Oats & Bran & Oats \\
\hline $\begin{array}{r}1 \\
2 \\
3 \\
4 \\
5 \\
6 \\
7 \\
8 \\
9 \\
10\end{array}$ & $\begin{array}{l}3 \longrightarrow \\
3 \longrightarrow \\
3 \longrightarrow \\
3 \longrightarrow \\
3 \longrightarrow \\
4 \longrightarrow \\
4 \longrightarrow \\
4 \longrightarrow \\
3 \longrightarrow \\
3 \longrightarrow\end{array}$ & $\begin{array}{l}6 \longrightarrow \\
5 \longrightarrow \\
4 \longrightarrow \\
3 \longrightarrow \\
2 \longrightarrow \\
\stackrel{\longrightarrow}{\longrightarrow} \\
\stackrel{\longrightarrow}{\longrightarrow} \\
\longrightarrow\end{array}$ & $\begin{array}{l}3 \\
4 \\
2 \\
2 \\
1 \\
6 \longrightarrow \\
4 \longrightarrow \\
1 \longrightarrow \\
1 \longrightarrow \\
1 \longrightarrow\end{array}$ & $\begin{array}{l}- \\
- \\
- \\
- \\
\overline{4} \\
6 \\
3 \\
2 \\
1\end{array}$ \\
\hline Mean & $3 \cdot 3$ & & $2 \cdot 5$ & 1 \\
\hline
\end{tabular}

Table II Transit times (days) in 10 subjects undergoing a double blind cross-over comparison of bran and ground oatflakes. 
3.3 days; when the subjects were taking bran it was 2.5 days, while on oats it was 3.6 days (table II). Transit was faster with bran than with oats in eight subjects, slower in one and the same in one. When the bran period was compared with the immediately preceding one (oats or no supplement), transit time was seen to decrease from a mean of 3.8 to 2.5 days $(t=2.75, P<0.025)$. When the oats period was compared with the previous one (bran or no supplement), there was no significant change by the paired $t$ test, the mean transit times being 2.8 and 3.6 days respectively.

\section{Discussion}

Within the limits of the methods used, these studies confirm that wheat bran accelerates intestinal transit, at least when it is initially three days or longer. The crossover comparison was intended as a double-blind study, but the subjects may well have been aware of differences in texture and taste between bran and ground oats. Nevertheless it is likely that the design of this study minimized any psychological influences upon intestinal behaviour, and therefore that the observed effect of bran was a genuine physical one. It is likely that this effect of bran is due to its high content of cellulose and hemicelluloses, since it and other foods rich in these materials are known to expand and soften the stool (Cowgill and Anderson, 1932; Morgan, 1934; Williams and Olmsted, 1936). Pharmaceutical preparations based on carboxymethyl cellulose (Celevac) and hemicellulose-rich seedcoats (Isogel, Metamucil) are widely prescribed for constipation.

The technique used in these studies for measuring transit time has poor reproducibility; Hinton et al (1969) found variations of up to two days on repeated studies in the same individual. For more detailed studies of the effects of bran on transit, for example to establish dose-response curves, it will be necessary to develop a more reproducible technique. This does not alter or even minimize the fact that significant effects of bran have been revealed in the present short-term studies. Whether these effects will be maintained over a prolonged period, or tolerance to bran will develop, remains to be determined.

Two different types of bran were used in these studies. Although both varieties seemed to accelerate slow transit it cannot be assumed that all forms of bran are equally effective. At a dose of $20 \mathrm{~g}$ daily, Kirwan et al (1974) found that fine bran had no influence on transit time in five subjects. However, they also showed that fine bran contains less fibre than coarse bran. Our studies show that fine bran is effective if given in a large enough dose.
The finding that transit slowed down in all four subjects with a transit time of one day when they were given bran is in agreement with the report of Harvey et al (1973) but is hard to explain. In patients with the irritable bowel syndrome, bran seems sometimes to relieve diarrhoea as well as constipation, as do pharmaceutical bulking agents. The boys with a one-day transit did not complain of diarrhoea, but it is possible that they had a subclinical form of the irritable bowel syndrome. Certainly, diverticular disease, which resembles the irritable bowel syndrome in both its symptoms and its pressure responses (Painter and Truelove, 1964; Wangel and Deller, 1965), is very often asymptomatic. This speculation needs to be tested by more extensive studies of colonic motility in apparently healthy subjects. It might be instructive to compare the motility pattern of the British population with that of a primitive community where the diet is unrefined, and thus rich in fibre. In rural Africans, transit is characteristically rapid, averaging 33-36 hours, but this is associated with the passage of much heavier stools than are customary in Britain (Burkitt et al, 1972).

The poor correlation between transit time and bowel frequency may be due in part to the inherent variability of our method for measuring transit rate. However, it does suggest that the frequency of defaecation is a poor guide to intestinal transit rate. A better guide may be stool consistency, but this was not evaluated in the present study.

This investigation does not answer the question whether it is desirable to accelerate intestinal transit in asymptomatic subjects. However, if it is desired to do this, then bran has certain advantages over pharmaceutical preparations. It is natural and cheap, and easily taken with other foods such as breakfast cereals and soups.

We are grateful to the subjects who volunteered for this study, to the radiology staff who took the radiographs, to Allinson's Limited for supplying bran, and to Professor A. E. Read for allowing us to study his patients. The school study was suggested by Mr D. P. Burkitt, FRS.

\section{References}

Burkitt, D. P., Walker, A. R. P., and Painter, N. S. (1972). Effect of dietary fibre on stools and transit-times, and its role in the causation of disease. Lancet, 2, 1408-1412.

Cowgill, G. R., and Anderson, W. E. (1932). Laxative effects , wheat bran and washed bran in healthy men: a comparative study. J. Amer. med. Ass., 98, 1866-1875.

Eastwood, M. A., Kirkpatrick, J. R., Mitchell, W. D., Bone, A., and Hamilton, T. (1973). Effects of dietary supplements of wheat bran and cellulose on faeces and bowel function. Brit. med. J., 4, 392-394.

Harvey, R. F., Pomare, E. W., and Heaton, K. W. (1973). Effects of increased dietary fibre on intestinal transit. Lancet, 1, 12781280. 
Hinton, J. M., Lennard-Jones. J. E., and Young, A. C. (1969). A new method for studying gut transit times using radiopaque markers. Gut. 10, 842-847.

Kirwan, W. O., Smith, A. N., McConnell. A. A., Mitchell, W. D., and Eastwood, M. A. (1974). Action of different bran preparations on colonic function. Brit. med., J., 4, 187-189.

Morgan, H. (1934). The laxative effect of a regenerated cellulose in the diet: its influence on mineral retention. J. Amer. med. Ass., 102, 995-997.

Painter, N. S., and Truelove, S. C. (1964). The intraluminal pressure patterns in diverticulosis of the colon. Gut, 5, 201-213.
Walker, A. R. P. (1947). The effect of recent changes of food habits on bowel motility. S. Afr. med. J., 21, 590-596.

Walker, A. R. P. (1974). Dietary fibre and the pattern of diseases. Ann. intern. Med., 80, 663-664.

Wangel, A. G., and Deller, D. J. (1965). Intestinal motility in man. III. Mechanisms of constipation and diarrhea with particular reference to the irritable colon syndrome. Gastroenterology, 48, 69-84.

Williams, R. D., and Olmsted, W. H. (1936). The manner in which food controls the bulk of the feces. Ann. intern. Med., 10, 717-727.

\section{The February 1975 Issue}

\section{THE FEBRUARY 1975 ISSUE CONTAINS THE FOLLOWING PAPERS}

A British family with hereditary pancreatitis J. R. SIBERT

Influence of exocrine and endocrine pancreatic function on intestinal brush border enzymatic activities W. F. CASPARY, K. WINCKLER, P. G. LANKISCH, AND W. CREUTZFELDT

The effect of cholestyramine on intestinal absorption R. J. WEST AND J. K. LLOYD

The exsorption characteristics of various sugars A. T. R. AXON AND B. CREAMER

Influence of dehydrocholate and taurocholate on bromsulphthalein uptake, storage, and excretion in the dog Y. DELAGE, S. ERLINGER, M. DUVAL, AND J.-P. BENHAMOU

Assessment of small bowel function in the elderly using a modified xylose tolerance test S. G. P. WEBSTER AND J. T. LEEMING

Hypersensitivity reactions in the small intestine I Thymus dependence of experimental 'partial villous atrophy' ANNE FERGUSON AND ELLEN E. E. JARRETT

Mechanisms of lipid loss from the small intestinal mucosa RICHARD WALDRAM
The distribution of mucosal antibodies in the bowel of patients with Crohn's disease F. H. Y. GREEN AND H. FOX

Function and structure of the mucosa of continent ileostomy reservoirs in dogs B. PHILIPSON, N. G. KOCK, J. W. L. ROBINSON, H. MENGE, AND V. MIRKOVITCH

Response of the human cardiac sphincter to circulating prostaglandins $F_{2_{\alpha}}$ and $E_{2}$ and to anti-inflammatory drugs J. B. DILAWARI, A. NEWMAN, J. POLEO, AND J. J. MISIEWICZ

Acid-base and metabolic disturbances in fulminant hepatic failure C. O. RECORD, R. A. ILES, R. D. COHEN, AND ROGER WILLIAMS

The effects of fast neutrons on inoperable carcinoma of the stomach MARY CATTERALL, DEREK KINGSLEY, GILBERT LAWRENCE, JOHN GRAINGER, AND JOHN SPENCER

\section{Progress report}

Pancreatic 'extracts in the treatment of pancreatic exocrine insufficiency J. H. B. SAUNDERS AND K. G. WORMSLEY

Notes and activities

Copies are still available and may be obtained from the PUBLISHING MANAGER, BRITISH MEDICAL ASSOCIATION, TAVISTOCK SQUARE, LONDON, WC1 $9 \mathrm{JR}$, price $£ 2 \cdot 00$, including postage 